\title{
Application of a Methodology Analyzing User Frustration
}

\section{Gene K. Rinkel and Patricia McCandless}

A user satisfaction study was undertaken at the University of Illinois at Urbana-Champaign in an attempt to demonstrate and analyze an application of the Kantor branching analysis of user frustration in another environment. The impact of an automated circulation system with public access to use availability of materials was monitored as was direct user access and partially controlled access to materials. The paper also discusses satisfaction rates and causes of user frustration in relation to academic status and prior use experience. The results support the concept that a hierarchy of categories provides a useful methodology for analysis of user frustration, but the scope and definition of those categories must be environment specific.

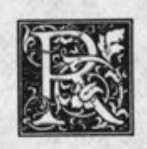

ecent library literature includes a number of studies on library effectiveness considered in relation to a given set of users and book availability that employ the techniques of operations research. Various suggestions have been made regarding appropriate types of performance measures. ${ }^{2}$ However, as yet there are no universally accepted standards or methods for the study of library effectiveness.

Capability indexes and satisfaction indexes of library effectiveness are among those measures gaining increasing acceptance for evaluating library performance. ${ }^{3}$ Some form of capability index appears to be the appropriate tool for collection evaluation and is especially valuable for selection or analysis of research collections. Satisfaction indexes tend to address the delivery of services to fulfill expressed demand. These measures are complementary in that improvement of immediate or expressed demand for titles should also improve the long-range research values of a collection. In light of current budget re- strictions, further refinement of a satisfaction index could provide the basis for more efficient use of existing resources.

User satisfaction is a loosely defined concept in contemporary librarianship. It has frequently been qualified by terms such as immediate (time related) or by source (i.e., local versus interlibrary or network lending implying length of loan, delivery time, etc.) or by complexity of the access process ranging from hands-on browsing, which allows almost instantaneous satisfaction of a newly discovered need, to reference assistance in providing either bibliographic information or specific facts by use of online retrieval services. Generally the term satisfaction index has been restricted to specific document requests as a measure of the percentage of bibliographic items immediately obtained or delivered. Widely varying satisfaction rates have been documented in various size collections and environments. ${ }^{4}$ Further application of this and other indexes in a wide variety of environments is needed to develop preciseness. Clearly, develop-

Gene K. Rinkel is with the General Services Division, and Patricia McCandless is assistant to the director of public services, University of Illinois Library at Urbana-Champaign. At the time of the study the authors were circulation librarian and LCS coordinator for public services, respectively, University Libraries, University of Illinois at Urbana-Champaign. 
ment and applications of these measures are desirable if they are also to provide standards for comparability in evaluation of library services. Refinement of such measures would also benefit the evaluation of the delivery of library services through developing networks.

\section{RESEARCH DESIGN}

A promising and practical method for analyzing library effectiveness uses such a satisfaction index but extends it by allowing comparison of sources of user frustration within and among a variety of library environments. The hierarchy proposed by P. B. Kantor and used at Case Western identified "parameters characterizing the causal factors which inhibit patrons from finding the items they seek. "' Application of such a measure across a variety of libraries and in the context of specific environments should not only contribute toward establishing standards for satisfaction levels but also identify further factors that if addressed would increase library effectiveness.

The present study seeks to demonstrate and analyze an application of that method in another environment. A modified version of the Kantor categories was applied to the general library stacks of the University of Illinois at Urbana-Champaign (UIUC) in November 1980. The University of Illinois at Urbana-Champaign is a statesupported institution with an enrollment of 34,376 and a faculty of 2,176 . The library system consists of thirty-five departmental units, the largest being the general bookstacks with approximately four million volumes. An additional two million volumes are housed in other units on campus, half of which are located in the main library building that houses the bookstacks. The bookstacks' collection represents older materials transferred from other units and collection areas where no departmental unit exists. The bookstacks are closed except to faculty and graduate students, who are encouraged to enter and retrieve their own materials. Some undergraduates also have stacks access while working on special projects. Assigned study carrels in the stacks for faculty and graduate students contribute to a sense of "open" stacks for those patrons. A desk paging service is provided for undergraduates and the general public. With the exception of several thousand items kept in a semi-rare area, all items in the bookstacks circulate: periodicals, serials, and microforms as well as books.

The UIUC Library uses an online circulation system, Library Computer System, which, in addition to handling circulation functions, permits known-item searching ${ }^{7}$ with copy and circulation status available on any one of ninety-six LCS terminals located in departmental units around campus. At the time of the study, five terminals in the card catalog area were for public use and patrons are encouraged to use LCS to check for location, circulation status, and availability.

In this application, the addition of a variable Pbib to the four reported in the Case Western study ${ }^{8}$ was considered desirable. The researchers felt $\mathrm{Pbib}$ was warranted to identify the components of user failure while maintaining analysis of the logical sequence of a user's search for a given item. Later applications at Case Western have also included a similar variable in the hierarchy. ${ }^{9} P b i b$ is a user variable with failure to locate a copy attributed to not finding a call number for the item sought, failure to report the call number correctly and/or completely, and the inability to determine the location of copies, i.e., failure to use the card catalog and/or LCS competently.

Satisfaction in this application was defined as obtaining material within one hour for known-item requests whether by paging or direct access. Several major differences from the Case Western study should be noted: the larger collection at UIUC with some duplication in other library units; the presence of an automated circulation system with public access for known-item searching to determine ownership and copy and circulation status; the inclusion of all circulating materials, all serials and microforms as well as monographs; and limited or controlled access for various users as opposed to an open collection. Furthermore, this study also examines satisfaction rates for specific user groups: faculty, graduate and under- 
graduate students, and courtesy borrowers.

\section{METHOD}

On fifteen randomly selected days in November 1980, representing a busy season of the regular fall semester, a questionnaire (see appendix A) was distributed to users seeking specific library materials from the general bookstacks. The format of the questionnaire provided space for author and title of one to three specific items sought on the current visit of the user to the stacks. It also included factual questions providing information on whether the users looked, paged, requested a search, and obtained the item sought. Other questions provided information about the users and their approach and about the requested material. Although the unusual problems accompanying data collection by questionnaire were encountered, an attempt was made to minimize subjective user judgments and reduce problems of recall by asking only short factual questions regarding the present visit to the stacks. An exception was a question requiring selfcharacterization of the user's borrowing experience during the current semester.

The sample reflects two broad user groups coming to the general stacks for known items. One target population was primarily faculty, staff, and graduate students (many with study carrels within the stacks). A second environment sampled involved a distinctly undergraduate population and courtesy borrowers who request materials from the stacks through a paging service at the circulation desk. The samples were taken during a time of class term paper demand and included some queueing of those using the desk service. Both of these groups interact: some with stacks access also request paging service and searching.

Pre-sample test trials resulted in design changes to the questionnaire and data collection procedures for the subsamples. Using past circulation figures, the researchers concluded that approximately two-thirds of the circulation was from users with stacks access. A random sample was stratified proportionately between users with stacks access and those using the desk paging service. Although the same questionnaire was distributed to both sample groups, it was systematically distributed to each tenth user entering the stacks on the sample days and to a user at the circulation desk when a randomly set beeper sounded. Three hundred thirtynine or 63 percent of those with direct access accepted forms and of those 74.9 percent returned them. Sixty-two or 18.3 percent of those returning forms indicated they were using their study carrels or browsing but not seeking specific items. One hundred forty forms were distributed to those using the paging service with a 73 percent return rate of 102 forms. These samples were analyzed separately and in combination with use of the Statistical Package for the Social Sciences ${ }^{10}$ to provide a clearer delineation of the user population and the effects of paging versus stacks access. Frequencies and crosstabs of selected variables in relation to satisfaction were examined.

The questionnaires were coded to allow analysis of each as a whole and individual requests regardless of how many were from one user. A combined sample of 509 cases was reported on 379 forms. All user groups were represented; library staff and repeat individuals were not excluded. Follow-up on each case was completed daily by the researchers, with clerical assistance, to determine the causes of failure. Coding was done by the authors and cross-checked to ensure reliability.

\section{FINDINGS}

Table 1 presents the results of the survey of satisfied and unsatisfied requests for library materials at UIUC in November 1980. The notation is as follows:

$W=$ total number of requests.

$S=$ number of immediately satisfied requests.

$P=$ number of unsatisfied requests. These requests were classified into five categories:

$P a c q=$ number of unsatisfied requests attributable to acquisition failure (not acquired, not yet in database or card catalog, all copies withdrawn, specific edition not 
TABLE 1

RESULTS OF THE UIUC GENERAL BOOKSTACKS USER STUDY-NOVEMBER 1980

\begin{tabular}{lcccc}
\hline \hline & Paged & $\begin{array}{c}\text { Direct } \\
\text { Access }\end{array}$ & Combined & Symbol \\
\hline $\begin{array}{l}\text { I. Total number of requests } \\
\text { II. Number immediately sat- }\end{array}$ & 193 & 316 & 509 & W \\
isfied by a stacks copy & 138 & 228 & 366 & $S$ \\
$\begin{array}{l}\text { III. Distribution of unsatis- } \\
\text { fied requests: }\end{array}$ & 55 & 88 & 143 & $P$ \\
A. Number of tiles not & 4 & 6 & 10 & Pacq \\
B. Numired & 17 & 31 & 48 & Pbib \\
$\begin{array}{l}\text { Grapher of bibio- } \\
\text { C. Number of items }\end{array}$ & 15 & 14 & 29 & Pcir \\
D. Number of library & 11 & 14 & 25 & Plib \\
E. Nulfunctions & 8 & 23 & 31 & Puser \\
\hline
\end{tabular}

owned, unpublished).

$P b i b=$ number of unsatisfied requests attributable to bibliographic errors (call number not found, incorrect or incomplete call number, location not stacks or copies available only in other units).

Pcir $=$ number of unsatisfied requests attributable to the item being in circulation (on loan to individual user, on reserve, on loan to interlibrary loan, on loan to another unit).

Plib $=$ number of unsatisfied requests attributable to library malfunction (error in card catalog or LCS, housed in special location within stacks, paging failure, reshelving delays, misshelved, missing after search).

Puser $=$ number of unsatisfied requests attributable to user errors (orientation to stacks arrangement, special markings/location). In the paging sample, Puser represents library staff performance.

Sample sizes were too small to analyze subcategories of reasons for failure.

Figure 1 and table 2 present the satisfaction rates attributable to the potential sources of frustration with their standard error using the Kantor branching analysis. A test was made of the difference between the proportions satisfied in the subsamples paging and direct access, using formula 1 to weigh for sample size. Formula 2 was applied to provide normalized $Z$ scores. The authors concluded that overall satisfaction rates represent a common population.

$$
\begin{aligned}
\text { Pest } & =\frac{N 1 p 1+N 2 p 2}{N} \\
Z & =\frac{\frac{p 1-p 2}{p(1-p) N}}{N 1+N 2}
\end{aligned}
$$

Table 3 examines satisfaction rates by status as stratified by size of each status in the sample. The results show that users of the general bookstacks at UIUC are satisfied at approximately the same level for all categories of borrowers.

The relatively high satisfaction rates reported here may be attributed to several factors that merit further study. The size of the collection and its organization into departmental units undoubtedly improved user satisfaction by providing a higher proportion of multiple copies for frequently used materials. LCS as an element in the context of Pbib may have systematically screened $P$ cir requests from the sample while increasing overall satisfaction by helping to locate another available copy. Since LCS shows missing copies, copies that have been borrowed, and copies on reserve, in binding, etc., patrons using LCS learn the potential availability of a sought item much sooner than they would have otherwise. Some patrons may not have requested or reported items they knew were in circulation or were housed in another unit, although at UIUC holds are frequently placed on copies in circulation. The questionnaire, as an instrument, while less obtrusive than an in- 

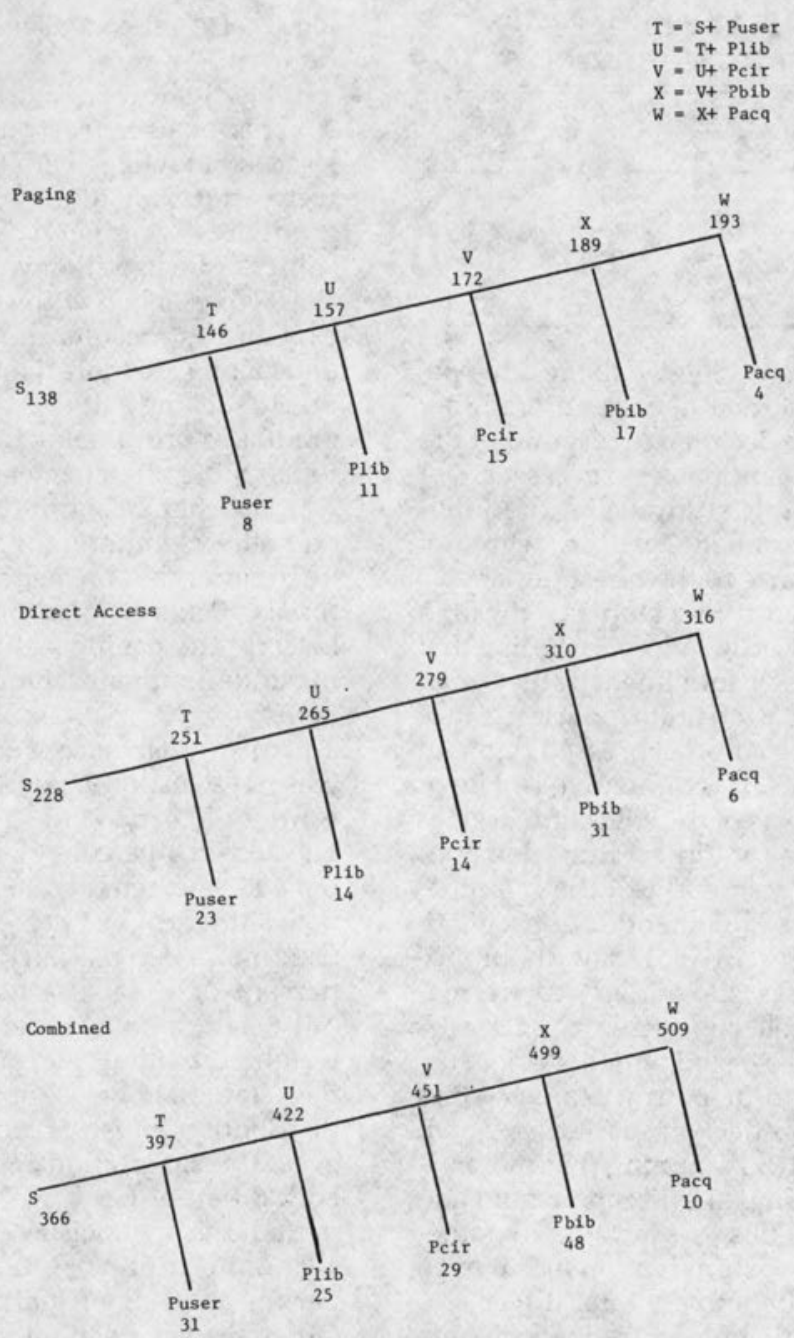

FIGURE 1

Satisfaction Rates

TABLE 2

MEASURES OF PERFORMANCE FOR THE GENERAL BOOKSTACKS FROM THE OUTCOME OF REQUESTS FOR MATERIALS-NOVEMBER 1980

\begin{tabular}{lcccccr}
\hline \hline & $\begin{array}{c}\text { Paged } \\
\text { Percent }\end{array}$ & $\begin{array}{c}\text { Direct } \\
\text { Access } \\
\text { Percent }\end{array}$ & $\begin{array}{c}\text { Combined } \\
\text { Percent }\end{array}$ & $\begin{array}{c}\text { Paged } \\
\text { Percent }\end{array}$ & $\begin{array}{c}\text { Standard Error } \\
\text { Direct } \\
\text { Access } \\
\text { Percent }\end{array}$ & $\begin{array}{c}\text { Combined } \\
\text { Percent }\end{array}$ \\
\hline Acquisitions Pacg =X/W & 97.93 & 98.10 & 98.04 & 1.02 & .77 & .61 \\
Bibliographic Pbib =V/X & 91.00 & 90.00 & 90.38 & 2.08 & 1.70 & 1.32 \\
Circulation Pcir $=U / V$ & 91.28 & 94.98 & 93.57 & 2.15 & 1.31 & 1.15 \\
Library Plib $=T / U$ & 92.99 & 94.72 & 94.08 & 2.04 & 1.37 & 1.15 \\
Users Puser $=S / T$ & 94.52 & 90.84 & 92.19 & 1.88 & 1.82 & 1.35 \\
Satisfaction level S/W & 7.150 & 72.15 & 71.91 & 3.25 & 2.52 & 1.99 \\
\hline
\end{tabular}


TABLE 3

TOTAL SATISFIED BY STATUS

\begin{tabular}{lccc}
\hline \hline & $\begin{array}{c}\text { Percent of } \\
\text { Requests } \\
\text { by Status }\end{array}$ & $\begin{array}{c}\text { Percent of } \\
\text { Status } \\
\text { in Sample }\end{array}$ & $\begin{array}{c}\text { Percent of } \\
\text { Total } \\
\text { Satisfied }\end{array}$ \\
\hline Undergrads & 74.8 & 40.4 & 40.9 \\
Graduates & 74.7 & 39.1 & 39.3 \\
$\begin{array}{l}\text { Faculty } \\
\text { Courtesy }\end{array}$ & 66.7 & 10.1 & 8.7 \\
Borrowers & 77.3 & 10.5 & 11.1 \\
\hline
\end{tabular}

terview, may have skewed the results: patrons unsure of their needs and/or library skills may have declined to respond or did so only with identifiable "successes." A replication of this study using the interview technique might test the degree of selective response to the questionnaire.

Consistent with other studies is the high performance of acquisitions, a finding that may suggest self-fulfillment rather than merely sound acquisition policies. Since this index is based on expressed demand for specific titles, it is difficult to isolate or control the effects of the collection itself as a bibliographic tool in creating demand. Future research should test the hypothesis that expressed demand for specific titles is directly correlated with bibliographic access provided to items, regardless of collection size.

The study also tested whether prior successful use and/or patron status would have a positive effect on success as shown in tables 4 and 5 . Assuming that more experience in using the library would improve library skills, the authors hypothesized that extensive use would correspond with success rate. It was also hypothesized that undergraduates would be less successful than graduates and/or faculty because of limited bibliographic skills and knowledge of library procedures. Presumably, a faculty member who is a heavy library user should be more successful than the freshman or other user who had used the library only a few times. The results at UIUC, as exhibited in table 4 , show significance at the .05 or better level where prior use improved skills in using the desk paging service. In table 4 the variable Puser, significant in the paging sample at .0015 , represents the interaction of the user and the desk staff receiving the request. Use by Pbib, significant at
.0003 , also reflects user and staff interaction.

Table 5 shows crosstabs of status and sources of user frustration and demonstrates that while overall satisfaction rates were approximately the same for undergraduates, graduates, and faculty, the sources of frustration were not the same. Pacq, crosstabbed with status, was significant and the results show that graduates and faculty are more likely to be frustrated due to seeking a title not acquired. Undergraduates presumably find substitute materials more often to meet their needs. Pbib was also significant in the paging sample and reflects undergraduate errors primarily in serial citations when requesting materials. Pcir was significant at the .0115 level for the paging sample, again reflecting undergraduates' requests for the same items.

Status by format of requested material was noteworthy. Undergraduates, representing 40.4 percent of the sample, requested 48.4 percent of the periodicals and only 24.3 percent of serials, whereas graduate students ( 39.1 percent of the sample) used more serials. Fifty-eight and a half percent of serial use was graduate and only 34.9 percent periodicals. When weighted by their percentage of the sample, status showed approximately equal distribution in use of monographs. However, the satisfaction rate was not markedly different between monographs and periodicals or serials in either subsample.

The questionnaire technique did not permit analysis of bibliographic failure. Other studies have and should continue to explore the patron's use of the card catalog, and similar studies of LCS are needed to provide insight for those engaged in bibliographic instruction. The completeness and accuracy of the user's citation, his/her approach and skill in using the card catalog, whether LCS commands were structured and typed accurately, and the user's interpretation of either the card or machine record are questions that should be examined in detail.

\section{CONCLUSION}

The application of Kantor's branching analysis in this environment shows that 
TABLE 4

CROSSTABS OF USE WITH

SOURCES OF USER FRUSTRATION

\begin{tabular}{|c|c|c|c|}
\hline & Paging & $\begin{array}{c}\text { Direct } \\
\text { Access } \\
\end{array}$ & Combined \\
\hline $\begin{array}{l}\text { Use by Pacq } \\
\text { Significance of } X^{2} \\
\text { Cramer's } V \\
\text { Use by Pbib } \\
\text { Significance of } X^{2} \\
\text { Cramer's } V \\
\text { Use by Pcir } \\
\text { Significance of } X^{2} \\
\text { Cramer's V } \\
\text { Use by Plib } \\
\text { Significance of } X^{2} \\
\text { Cramer's } V \\
\text { Use by Puser } \\
\text { Significance of } X^{2} \\
\text { Cramer's } V\end{array}$ & $\begin{array}{c}N=195 \\
.5254 \\
.12804 \\
N=190 \\
.0003 \\
.33153 \\
N=170 \\
.8449 \\
.09063 \\
N=154 \\
.8961 \\
.08407 \\
N=72 \\
.0015 \\
.49402\end{array}$ & $\begin{array}{c}N=307 \\
.6753 \\
.08730 \\
N=296 \\
.0653 \\
.17280 \\
N=262 \\
.9965 \\
.02561 \\
N=245 \\
.1505 \\
.16581 \\
N=248 \\
.1171 \\
.17250\end{array}$ & $\begin{array}{c}N=502 \\
.6491 \\
.70722 \\
N=486 \\
.0020 \\
.18632 \\
N=432 \\
.7594 \\
.06582 \\
N=399 \\
.4998 \\
.09173 \\
N=320 \\
.0009 \\
.24210\end{array}$ \\
\hline
\end{tabular}

TABLE 5

CROSSTABS OF STATUS WITH SOURCES OF USER FRUSTRATION

\begin{tabular}{|c|c|c|c|}
\hline & Paging & $\begin{array}{l}\text { Direct } \\
\text { Access }\end{array}$ & Combined \\
\hline $\begin{array}{l}\text { Status by Pacq } \\
\text { Significan of } X^{2}\end{array}$ & $N=195$ & $N=310$ & $N=505$ \\
\hline Cramer's $V$ & .59652 & $\begin{array}{l}.8805 \\
.09917\end{array}$ & $\begin{array}{l}.0263 \\
.17728\end{array}$ \\
\hline Status by Pbib & $N=190$ & $N=299$ & $N=489$ \\
\hline Significance of $X^{2}$ & .0204 & .1969 & .5720 \\
\hline Cramer's V & .29535 & .18156 & .10822 \\
\hline Status by Pcir & $N=170$ & $N=265$ & $N=435$ \\
\hline Significance of $X^{2}$ & .0115 & .5608 & .1837 \\
\hline Cramer's V & .32632 & .14821 & .15228 \\
\hline Status by Plib & $N=154$ & $N=247$ & $N=401$ \\
\hline Significance of $X^{2}$ & .8943 & .7007 & .7995 \\
\hline Cramer's V & .12115 & .13744 & 09769 \\
\hline $\begin{array}{l}\text { Status by Puser } \\
\text { Significance } X^{2}\end{array}$ & $N=72$ & $N=251$ & $N=323$ \\
\hline $\begin{array}{l}\text { Significance of } X^{2} \\
\text { Cramer's } V\end{array}$ & $\begin{array}{l}.1443 \\
.36443\end{array}$ & $\begin{array}{l}.3649 \\
.17453\end{array}$ & $\begin{array}{l}.1577 \\
.18104\end{array}$ \\
\hline
\end{tabular}

the concept of a hierarchy of categories does provide a useful methodology for analysis of user frustration. However, the researchers have concluded that the content and definition of these categories must be environment specific. In this environment, for instance, the introduction of LCS, which provides circulation information on availability of copies, may have reduced the measured frustration rate or caused it to occur earlier in the search process. The content of subcategories, although logically related, cannot be fixed for every environment. The creation of categories is a conceptualization that can be modified to isolate specific factors for study. If the categories are narrowly de- fined operationally, they may be applied to each step in a search process. The limitations are primarily those of practical application. Costs of sample size and management's uses of the results should provide guidelines for logical development of additional categories to be studied.

An overall performance measure in the form of a satisfaction index would clearly be useful in comparisons among similar libraries or branches of a library. A measure of user satisfaction that identifies the sources of user frustration such as that used here allows administrators to target specific factors or programs, which, if improved, would increase overall perform- 
ance with a minimum investment. It is especially meaningful when employed as a pre/post technique following administrative, organizational, or policy changes. ${ }^{11} \mathrm{~A}$ potential advantage of the Kantor concept, while running counter to direct comparability, is that it does allow further elaboration in identifying sources of frustration in specific environments. Although the addition of categories alters the distribution of individual indexes, which are then not directly comparable with other libraries, the overall satisfaction rate for a library would remain un- changed but redistributed to reflect relative magnitudes in local sources of frustration. Following wider replication to determine appropriate subdivision of these variables, an agreed-upon set of categories and/or subcategories could become the basis for standardization. Practical application of the technique in terms of sample sizes required, may dictate a limited set of variables for standardized comparisons, while individual libraries could further subdivide those areas showing high user frustration for in-depth analysis.

\section{REFERENCES}

1. P. M. Morse, Library Effectiveness: A Systems Approach (Cambridge, Mass.: MIT Press, 1968).

2. F. W. Lancaster and Deanne McCutcheon, "Some Achievements and Limitations of Quantitative Procedures Applied to the Evaluation of Library Services," in Quantitative Measurement and Dynamic Library Service (Phoenix: Oryx Pr., 1978), p.12-30. See especially p.22-26 on Document Delivery Studies.

3. Ibid.

4. D. Gore, "Let Them Eat Cake while Reading Catalog Cards: An Essay on the Availability Problem," Library Journal 100:93-98 (15 Jan. 1975); Marjorie E. Murfin, "The Myth of Accessibility: Frustration and Failure in Retrieving Periodicals," Journal of Academic Librarianship 6:16-19 (March 1980).

5. T. Saracevic, W. M. Shaw, Jr., and P. B. Kantor, "Causes and Dynamics of User Frustration in an Academic Library," College \& Research Libraries 38:8 (Jan. 1977).

6. Paul B. Kantor, "Demand-Adjusted Shelf Availability Parameters," Journal of Academic Librarianship 7:78 (May 1981).

7. James F. Corey and Lynne M. Blair, "The Library Computer System at the University of Illinois," Illinois Libraries 60, no.4: 365-74 (April 1978).

8. Saracevic, Shaw, and Kantor, "Causes and Dynamics," p.7.

9. W. M. Shaw, Jr., "Longitudinal Studies of Book Availability," in Library Effectiveness: A State of the Art, Papers from a 1980 ALA Preconference (Chicago: American Library Assn., 1980), p.338-49.

10. Norman H. Nie and others, Statistical Package for the Social Sciences (2d ed.; New York: McGraw Hill, 1975).

11. Shaw, "Longitudinal Studies," p.338-49.

\section{APPENDIX A \\ UIUC GENERAL LIBRARY STACKS 1980/81 USER GROUP}

Please list up to three (3) books you are seeking on this trip to the library and check $(x)$ the appropriate columns.

Please list the author and title for each book you were seeking today even if you did not find the book in the system.

1. Author:

Title:

2. Author:

Title:

3. Author:

Title: 
CALL NUMBER

\section{Location}

How did you find the call number?

LCS

CARD CAT

OTHER

How did you find the location?

LCS

CARD CAT

OTHER

Did you get help with?

LCS

CARD CAT

Did you ask staff to?

PAGE BOOK

SEARCH

Did you look for book yourself today?

IN STACKS

Did you get book?

YES

NO

1. What is your current status at the University of Illinois at Urbana-Champaign? Freshman Sophomore Other Junior Senior Grad Student Faculty Visitor

2. What is your Department? (Faculty and Graduate Students) OR Major? (Undergraduates)

3. Approximately how many books have you borrowed from the library (all departments) this semester? Fewer than 5 5-10 11-20 21-30 More than 30

4. As you leave the stacks today, please drop this form into box marked "USER STUDY" at the Circulation Desk or Exit to the Stacks. Your cooperation in completing this form will enable the library to improve service to users of the stacks. Thank you. 